\title{
fMRI correlates for low frequency local field potentials appear as a spatiotemporal dynamic under multiple anesthetic conditions
}

\author{
Garth J Thompson*, Wen-Ju Pan, Matthew E Magnuson, Shella D Keilholz \\ From Twenty First Annual Computational Neuroscience Meeting: CNS*2012 \\ Decatur, GA, USA. 21-26 July 2012
}

In the previous decade, interest in the "functional connectivity" of the brain has greatly increased, but the nature of the signal underlying derived predictive metrics remains poorly understood [1]. A typical study uses functional magnetic resonance imaging (fMRI) and calculates regions of correlated low-frequency activity or "functional networks" when no task is being performed, the "resting state". However, unlike traditional block/ event based fMRI, the spontaneous fluctuations that determine such networks may not relate to a standard "hemodynamic response" to neural activity [2] and may be task and brain region dependent [1]. Ten rats were anesthetized with either isoflurane (iso) or dexmedetomidine (med). Each rat had simultaneous local field potentials (LFP) [3] recorded from implanted electrodes in bilateral primary somatosensory cortex (SI) simultaneously with single-slice fMRI of SI [4]. After preprocessing, signals were filtered to regions of significant spectral coherence $(0.04-0.18 \mathrm{~Hz}$ iso, $0.05-0.3 \mathrm{~Hz}$ med). Pearson correlation $\left(r_{\mathrm{t}}\right)$ was calculated between LFP signals at time shifts -10 s to 10 s relative to fMRI, at every fMRI voxel (Figure 1B). Instead of a simple hemodynamic response, the LFP correlates appeared both to have a component of spatial propagation (Figure 1B, white arrows), and alternation between positive and negative correlation. This was observed using both anesthesias and suggests that LFPs in coherent frequencies do not simply reflect local activation, but may instead be part of a large scale dynamic process. Using an fMRI-based algorithm validated in both anesthetized rats and awake humans [5], a spatiotemporal dynamic was produced that was highly similar to $r_{\mathrm{t}}$ (Figure 1C). Spatial correlation $\left(r_{\mathrm{s}}\right)$ between the two types of pattern reached a maximum at approximately the same shift
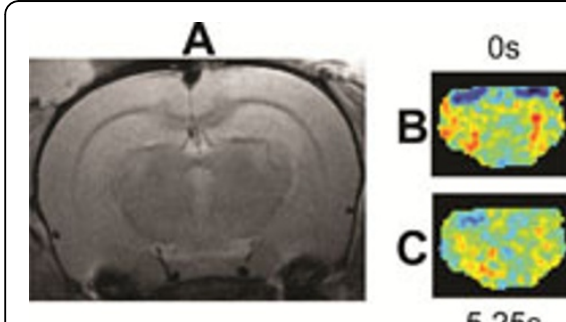

$5.25 \mathrm{~s}$

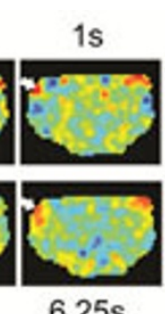

$6.25 \mathrm{~s}$

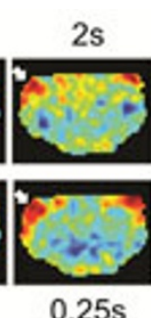

$0.25 \mathrm{~s}$

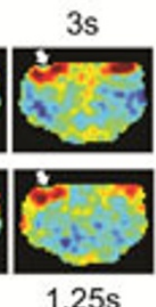

$1.25 \mathrm{~s}$

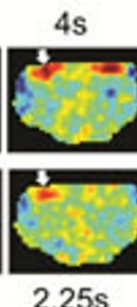

$2.25 \mathrm{~s}$

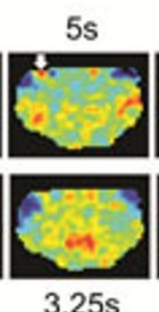

$3.25 \mathrm{~s}$
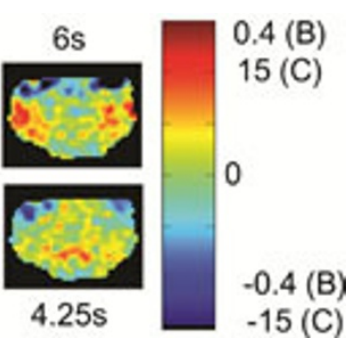

Figure 1 A. A coronal image of a rat's brain in the same plane as the fMRI images used in this study. B. (med) $r_{t}$ between LFP and fMRI at each voxel, times listed are the time shift of LFP prior to fMRI. C. (med) fMRI pattern from Majeed et al. algorithm [5], times listed are arbitrary, so they are shifted to match (B).

\footnotetext{
* Correspondence: garth@gatech.edu

Biomedical Engineering, Emory University and Georgia Institute of

Technology, Atlanta, GA 30306, USA
} 
between patterns in all rats, mean $r_{\mathrm{s}}=0.25$ (med) and mean $r_{\mathrm{s}}=0.23$ (iso), with mean $r_{\mathrm{s}}>0.10$ indicating significance at $\mathrm{p}<0.05$ when using boot-strapping and correcting for multiple comparisons [6]. These results suggest that the neural basis of functional networks may be more complex than a simple hemodynamic response and possibly contains contributions from large-scale neuromodulatory processes.

Published: 16 July 2012

\section{References}

1. Sadaghiani S, Hesselmann G, Friston KJ, Kleinschmidt A: The relation of ongoing brain activity, evoked neural responses, and cognition. Front Syst Neurosci 2010, 4:20.

2. Logothetis NK, Murayama $Y$, Augath M, Steffen T, Werner J, Oeltermann A: How not to study spontaneous activity. Neuroimage 2009, 45(4):1080-1089.

3. Logothetis NK, Pauls J, Augath M, Trinath T, Oeltermann A: Neurophysiological investigation of the basis of the fMRI signal. Nature 2001, 412(6843):150-157

4. Pan WJ, Thompson G, Magnuson M, Majeed W, Jaeger D, Keilholz S: Simultaneous FMRI and electrophysiology in the rodent brain. $J$ Vis Exp 2010, 42.

5. Majeed W, Magnuson M, Hasenkamp W, Schwarb H, Schumacher EH, Barsalou L, Keilholz SD: Spatiotemporal dynamics of low frequency BOLD fluctuations in rats and humans. Neuroimage 2011, 54(2):1140-1150.

6. Carvajal-Rodriguez A, de Una-Alvarez J, Rolan-Alvarez E: A new multitest correction (SGoF) that increases its statistical power when increasing the number of tests. BMC Bioinformatics 2009, 10:209.

doi:10.1186/1471-2202-13-S1-019

Cite this article as: Thompson et al.: fMRI correlates for low frequency local field potentials appear as a spatiotemporal dynamic under multiple anesthetic conditions. BMC Neuroscience 2012 13(Suppl 1):019.

\section{Submit your next manuscript to BioMed Central} and take full advantage of:

- Convenient online submission

- Thorough peer review

- No space constraints or color figure charges

- Immediate publication on acceptance

- Inclusion in PubMed, CAS, Scopus and Google Scholar

- Research which is freely available for redistribution

Submit your manuscript at www.biomedcentral.com/submit
C Biomed Central 